Article

\title{
Research on Physico-Chemical Properties of Diethyl Ether/Linseed Oil Blends for the Use as Fuel in Diesel Engines
}

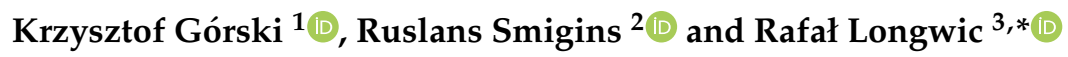 \\ 1 Faculty of Mechanical Engineering, Kazimierz Pulaski University of Technology and Humanities in Radom, \\ ul. Chrobrego 45, 26-200 Radom, Poland; krzysztof.gorski@uthrad.pl \\ 2 Faculty of Engineering, Latvia University of Life Sciences and Technologies, J. Cakstes blvd 5, \\ Jelgava, LV3001 Latvia; ruslans.smigins@llu.lv \\ 3 Faculty of Mechanical Engineering, Lublin University of Technology, ul. Nadbystrzycka 38D, \\ 20-618 Lublin, Poland \\ * Correspondence: r.longwic@pollub.pl; Tel.: +48-81-538-42-68
}

Received: 13 November 2020; Accepted: 10 December 2020; Published: 12 December 2020

check for updates

\begin{abstract}
Physico-chemical properties of diethyl ether/linseed oil (DEE/LO) fuel blends were empirically tested in this article for the first time. In particular, kinematic viscosity $(v)$, density $(\rho)$, lower heating value (LHV), cold filter plugging point (CFPP) and surface tension $(\sigma)$ were examined. For this research diethyl ether (DEE) was blended with linseed oil (LO) in volumetric ratios of 10\%, $20 \%$ and $30 \%$. Obtained results were compared with literature data of diethyl ether/rapeseed oil (DEE/RO) fuel blends get in previous research in such a way looking on differences also between oil types. It was found that DEE impacts significantly on the reduction of plant oil viscosity, density and surface tension and improve low temperature properties of tested oils. In particular, the addition of $10 \%$ DEE to LO effectively reduces its kinematic viscosity by $53 \%$ and even by $82 \%$ for the blend containing $30 \%$ DEE. Tested ether reduces density and surface tension of LO up to $6 \%$ and $25 \%$ respectively for the blends containing 30\% DEE. The measurements of the CFPP showed that DEE significantly improves the low temperature properties of LO. In the case of the blend containing 30\% DEE the CFPP can be lowered up to $-24{ }^{\circ} \mathrm{C}$. For this reason DEE/LO blends seem to be valuable as a fuel for diesel engines in the coldest season of the year. Moreover, DEE/LO blends have been tested in the engine research. Based on results it can be stated that the engine operated with LO results in worse performance compared with regular diesel fuel (DF). However, it was found that these disadvantages could be reduced with DEE as a component of the fuel mixture. Addition of this ether to LO improves the quality of obtained fuel blends. For this reason, the efficiency of DEE/LO blend combustion process is similar for the engine fuelled with regular diesel fuel. In this research it was confirmed that the smoke opacity reaches the highest value for the engine fuelled with plant oils. However, addition of $20 \%$ DEE reduces this emission to the value comparable for the engine operated with diesel fuel.
\end{abstract}

Keywords: linseed oil; diethyl ether; fuel properties; engine; testing

\section{Introduction}

Vegetable oil as a diesel engine fuel has been a subject of study for a long time, probably from the first usage of it in Rudolf Diesel invented engine. Although vegetable oils did not become so important a fuel source as fossil fuel as diesel predicted during exploitation of his engine with peanut oil, there was and still exist some areas where vegetable oils are requested and used, maintaining return to the idea of plant oils [1]. Usage of vegetable oils is usually outpointed by its main advantages 
over conventional diesel fuels: domestic production allowing to reduce dependency from imported diesel fuel, renewability, better lubricity, biodegradability and increasing of flash point. As any other alternative fuel it could outpoint also some disadvantages, which did not allow its rapid usage during the last decade: lower energy content, higher viscosity, compatibility, higher production price, etc. Despite different application problems vegetable oils can be successfully used in engines based on fuel or engine modification. More and more attention is turned on inedible vegetable oils affected by depletion of resources and necessity for edible oils as a food. Linseed instead of most popular rapeseed oil is practically used for industrial purposes, but based on its technical characteristics it can be used also as a fuel under certain conditions.

There are not many practical research or on-road trials concerning linseed oil due to previously mentioned factors, while there are also some research for oils with similar composition allowing one to make general conclusions. For example, Beg et al. [2] reported an increase of fuel consumption, exhaust gas temperature, $\mathrm{CO}$ emissions, smoke density and decrease of NOx using diesel fuel-linseed blends compared to regular diesel fuel. Other researchers [3] demonstrated significant difference in engine emissions in tests with mixtures of fuels having $5 \%$ and $9 \%$ of linseed oil addition to diesel fuel. Realizing experimental researches on D-245.12C diesel engine Markov et al. [3] found that even small addition of linseed oil to diesel fuel allows reduced toxic components in diesel exhaust, i.e., nitric oxides NOx, carbon monoxide $\mathrm{CO}$ and unburned hydrocarbons $\mathrm{HC}$.

Agarwal et al. [4] tested different blends of linseed oil $(10 \%, 20 \%, 30 \%$ and $50 \%, v / v)$ with diesel fuel and has found that blends with higher linseed oil addition are more efficient. Overall it is concluded that vegetable oils are not ideal fuels for diesel engine in case of operational (ignition, performance, etc.) and durability (deposit formation, lubrication oil dilution, etc.) problems, but also based on additional impact left by other physicochemical properties: viscosity, polyunsaturated character and extremely low volatility [4]. Based on that diesel engine operation with vegetable oil could be resulted in poor atomization, non-ideal fuel-air mixing and combustion, and finally in decrease in power and increase in fuel consumption. Different solutions exist to overcome such problems: transesterification, emulsification and blending. One of the most popular is transesterification allowing one to convert vegetable oil in ester in such a way of creating fuel with properties close to diesel fuel [5]. Another, more simplified and attractive alternative is blending vegetable oil with diesel fuel or oxygenate, which allow one to drastically reduce viscosity and increase the cold filter plugging point and cetane number. For one of the main blending problems, which is observed, its molecular structure remains unchanged hence the polyunsaturated character remains [4].

Improvement of oil properties could be realized using different oxygenated additives such as ethanol, methanol, ethyl-tert buthyl ether, diethyl ether (DEE), etc. The last one was chosen for this research. Diethyl ether, which is an organic compound and historically used as an anesthetic agent is expressed by its chemical formula $\mathrm{CH} 3 \mathrm{CH} 2-\mathrm{O}-\mathrm{CH} 2 \mathrm{CH}$. Produced from ethanol obtained from biomass in the dehydrating process, it also can be known as bio-DEE [6], showing its main advantages over diesel fuel. First of all, this type of fuel stands up with low viscosity values allowing one to reduce viscosity of the blend, where base fuel has viscosity higher than that of conventional diesel fuel, like plant oils. Combination of these values of both mentioned fuel types could give optimal viscosity necessary for diesel engine operation without preheating in the same time keeping lubricity at a reasonable level [7].

Research carried out with DEE as a fuel for diesel engines confirm that it can be used in different blends with other fuel types, i.e., diesel fuel, ethanol, biodiesel, biodiesel-diesel and ethanol-biodiesel-diesel. The literature shows that a limited number of works exists on the usage of vegetable oil/DEE fuel blends in diesel engines, which also provides limited information on its physicochemical and combustion properties.

Rakopoulos [7] used a standard, experimental, single-cylinder, four-stroke, high-speed direct injection (HSDI) diesel powered with cottonseed oil and its biodiesel (methyl ester) in blends with $20 \%$ $(v / v)$ of diethyl ether for research of combustion and exhaust emission characteristics. He reported 
lower smoke, NOx and CO emissions, but higher HC emissions for DEE blends than neat cottonseed oil or its neat biodiesel.

Krishna et al. [8] used diethyl ether as an oxygenated additive mixed with karanja oil in various proportions of $5 \%, 10 \%, 15 \%, 20 \%$ and $25 \%$ by volume in dual fuel operation 4 cylinder $39 \mathrm{~kW}$ diesel engine. They observed that for blends up to $15 \%$, CO emissions are lower than the corresponding values for diesel, while NOx emissions were significantly lower for the blends at lower loads. They also found that fuel consumption at a higher engine loads for the blend is higher than for pure diesel explaining it with the lower calorific value of the blends.

Geo et al. [9] used a single cylinder diesel engine with rated output of $4.4 \mathrm{~kW}$ at $1500 \mathrm{rpm}$ converted for operation in the DEE injection mode. Engine was operated on rubber seed oil as a single fuel with DEE injection at the flow rate of $100 \mathrm{~g} / \mathrm{h}, 150 \mathrm{~g} / \mathrm{h}$ and $200 \mathrm{~g} / \mathrm{h}$. They reported an increase of NOx emissions and reduction of hydrocarbon, carbon monoxide and smoke emissions, the last one explaining with "better combustion of injected fuel in the hotter combustion chamber by the early combustion of DEE". Besides that he confirmed that DEE injection to rubber seed oil results in reduced combustion duration from 47 to 44 crank angle (CA) degree due to the fast diffusion combustion rate in comparison to neat oil.

Delalibera et al. [10] analyzed diesel engine performance and emissions when fueled with pure linseed oil, preheated at $100^{\circ} \mathrm{C}$, at the injection pump inlet and at engine working temperature $\left(60^{\circ} \mathrm{C}\right)$ in short duration tests. Results confirmed a slight increase in exhaust gas temperature generally for preheated oil and slight reduction of smoke for non-preheated oil compared to diesel fuel, while smoke increased for preheated oil compared to diesel fuel. Fuel consumption for preheated oil presented lower variation when compared to non-preheated oil indicating that the engine operation for them was more stable. He confirmed that the engine without linseed oil preheating presents greater power loss compared to diesel fuel at the same time.

Krishnamoorthi et al. [11] used a single cylinder direct injection variable compression ratio test engine Kirloskar VCR in tests with blends of diesel fuel, bael oil and diethyl ether in various blending ratios. They confirmed that addition of DEE to bael oil and diesel reduced the peak cylinder pressure due to a lower calorific value of the DEE and wider spray pattern. It was also observed CO emission reduction explaining it with enhancement of the combustion process with the effect of DEE. There was also reported reduction of NOx emissions associated with an adequately lower value of peak combustion temperature due to DEE addition in such a way that reduces the calorific value of the blend.

Ibrahim [12] evaluated the effect of DEE/diesel fuel blends on diesel engine performance, selected combustion parameters and stability of engine work. He highlighted that DEE blended with diesel fuel improves engine performance. Additionally, higher thermal efficiency increased for the engine operated with DEE/diesel fuel blends. It should be pointed that the engine stability was slightly reduced.

Carvalho et al. [13] studied the effects of DEE in biodiesel-ethanol blends on emissions and performance of direct injection diesel engine. They concluded that DEE added in moderate concentration to the ethanol biodiesel mixture improves the engine efficiency and reduces NOx emissions.

There are not research on detailed analysis of physicochemical and combustion properties of linseed oil and DEE blends, while there exist research on physicochemical properties of rapeseed oil and DEE blends [14,15]. Therefore, the objective of this study was to test the effect of DEE/linseed oil fuel blends to evaluate the possibility for the use of such mixtures in diesel engines, and also making a comparison of obtained results with DEE/RO blends [14].

\section{Physicochemical Properties of Linseed Oil}

Linseed oil is one of the oils, which has an inherently high amount of mono- and polyunsaturated fatty acids [16] resulting in one of the longest ignition delays between all vegetable oils. Detailed research [16] of nine different vegetable oils has confirmed that mono- and polyunsaturated fatty acids 
those with two or more double bonds had mostly a greater effect on ignition delay than fatty acids with just one single double bond.

Possible linseed oil usage in diesel engine is strongly connected to the engine sensitivity on fuel injection and combustion, and one of the main parameters is viscosity. Viscosity, which is a measure of the resistance of fluid to a flow, is the most important parameter for all vegetable oils as it leaves an impact on the quality of fuel atomization. Linseed oil unlike the main vegetable oils stands out with lower viscosity, which is closer to the similar diesel fuel characteristics, if it is added to diesel fuel in a small amount, like $5 \%$ and $9 \%$ [3]. In spite of this linseed oil viscosity is still higher compared to diesel having higher resistance to break-up therefore increase of fuel density together with viscosity results in the decrease of the spray angle [17]. A viscosity increase requires more energy from the fuel pump and reduces the net power output from the engine [18].

Density, a measure of the mass per unit volume, is a temperature dependent parameter, which decreases linearly with increasing the temperature [19] and knowledge of this tendency is highly important in provision of fuel combustion and its analysis. Viscosity dependency could be observed also in the case of the addition of other fuels, like DEE [14], where values of density decrease with an increase of DEE by volume. In the case of blending it could be more simplified solution against heating, where Esteban et al. [19] have found that vegetable oils require preheating to $120^{\circ} \mathrm{C}$ minimally to match physical properties of diesel fuel concluding that temperature requirement depends on engine types and configurations. Besides the reduction of density during the heating it should be expected an increase of consumption based on lower energy content per volume in systems with mechanical injection control, where the fuel is volumetrically applied in the combustion chamber. This was also observed in research, where preheating reduced density of canola oil by $5.18 \%$ reflecting in the increase of consumption [20].

Besides viscosity and density, surface tension of fuel also leaves an impact on spray formation and especially on the formation of fuel drops. Higher surface tension coefficient increases the cohesive force, which circumvents the formation of smaller drops [18], which increase the evaporation rate and enhances the mixing of fuel vapor and air. Realization of such a process must be supported also by an adequate spray cone angle, which strongly depends on the nozzle size and liquid properties for a given injection pressure [21]. Research with biodiesel-diesel blends [18] confirmed that the spray cone angle increases with an increase in both ambient density and injection pressure differential suggesting using preheating of different fuel blends to achieve values equal to those of diesel fuel. Like other parameters, surface tension also is affected by the number of unsaturated bands and the fatty acid hydrocarbon chain length, where long fatty acid hydrocarbon chain tends to increase the surface tension [22]. Additionally, here preheating is not the best solution, as research [19] on different vegetable oil types shows that vegetable oils requires preheating at temperatures not lower than $120^{\circ} \mathrm{C}$ to reach surface tension values corresponding to diesel fuel at $40{ }^{\circ} \mathrm{C}$.

Cetane number is a dimensionless descriptor of the ignition quality of a diesel fuel, determined by unbranched chains of fatty acids similar to those of the n-alkanes of diesel fuel [23]. Chain length leaves an impact on cetane number, where decreasing of chain length reduce cetane number. There could be determined also the relationship between cetane number and ignition delay, where the higher cetane number determines shorter ignition delay. As previously it was mentioned, linseed oil has one of the longest ignition delays between vegetable oils and one of the smallest cetane number, 34.6 instead of 37.6 for rapeseed oil or 42.0 for palm oil [23]. Therefore, influence of increased unsaturation on the lowest cetane number is proven for linseed oil. An increase of cetane number is possible by blending oil with alcohols (like DEE), while the heating value of the blends will be practically in the same range.

Operability of diesel engine in low temperature climate zones is characterized by the cold filter plugging point (CFPP). The improper value of this parameter of fuel used in the low temperature climate and seasonal conditions can lead to crystal formation resulting in the restriction of flow through fuel lines and filters. This further can promote ignition problems. Like other analyzed parameters, also CFPP is mainly dependent on the fatty acid profile of the feedstock. The CFPP decreases with the 
increase of the total unsaturated fatty acid contents [24], which could be also confirmed in the case of LO instead of RO.

Lower heating value (LHV) is another parameter, which increases with chain length [23] while impact of its values is not so rapid as in the case of cetane number. Like density, heating value can be calculated if weighted averaging of the property values of the original components is known [18]. Most impact could be left by two components: hydrogen and oxygen. LHV decreases with an increase of oxygen and it could increase with an increase of hydrogen [25]. Most researchers [26] observed a drop of rated brake power in the case of reduced lower heating value of vegetable oils. LO presents lower heating value than diesel fuel, but almost similar to RO.

\section{Materials and Methods}

Linseed oil used in this study was produced by Iecavnieks and Co Ltd. situated in Iecava (Latvia), while DEE with purity $99.5 \%$ was bought from the POCH S.A. (Gliwice, Poland) chemical company. Selected physicochemical properties of the tested LO and DEE are listed in Table 1.

Table 1. Physicochemical characteristics of tested linseed oil and diethyl ether $[3,23,27]$.

\begin{tabular}{|c|c|c|c|}
\hline Properties & Linseed Oil & Diethyl Ether & Diesel Fuel \\
\hline Kinematic viscosity at $40^{\circ} \mathrm{C}, \mathrm{mm}^{2} / \mathrm{s}$ & 24.994 & 0.23 & 2.84 \\
\hline Density at $15^{\circ} \mathrm{C}, \mathrm{g} / \mathrm{mL}$ & 0.9319 & 0.71 & 0.83 \\
\hline Lower heating value, $\mathrm{MJ} / \mathrm{kg}$ & 37.9 & 33.9 & 42.8 \\
\hline Cold filter plugging point, ${ }^{\circ} \mathrm{C}$ & 16 & -40 & -10 \\
\hline Surface tension, $\mathrm{mN} / \mathrm{m}$ & 31.5 & 16.9 & 25.8 \\
\hline Flash point, ${ }^{\circ} \mathrm{C}$ & 220 & -40 & 71 \\
\hline Cetane number & 34.6 & $>125$ & 51.3 \\
\hline Cloud point, ${ }^{\circ} \mathrm{C}$ & 1.7 & - & - \\
\hline Pour point, ${ }^{\circ} \mathrm{C}$ & -15.0 & - & - \\
\hline \multicolumn{4}{|l|}{$\%$ content by mass } \\
\hline C & 77.8 & 64.9 & 86 \\
\hline $\mathrm{H}$ & 12.0 & 13.5 & 14 \\
\hline $\mathrm{O}$ & 10.2 & 21.6 & 0 \\
\hline
\end{tabular}

DEE was blended with LO in volumetric ratios of $10 \%, 20 \%$ and $30 \%$. These DEE/LO fuel blends are coded as follows: LO10, LO20 and LO30, respectively.

Measurements of physicochemical properties of DEE/LO blends were carried out at the Kazimierz Pulaski University of Technology and Humanities in Radom. Especially, the density and kinematic viscosity of the blends were tested according to requirements of EN ISO 3838 [28] and EN ISO 3104 [29] standards, respectively. Density determination of tested fuels was carried out by weighing pycnometer with a capacity $25 \mathrm{~cm}^{3}$. For kinematic viscosity measurements a capillary viscometer and the constant temperature bath made by Tamson Instruments BV were used. The heat of combustion of all fuel blends was expressed by the lower heating value (LHV) measured in agreement with the ASTM D240-02:2007 [30] procedure. In this test method the bomb calorimeter KL-10 made by PRCYZJA-BIT Co. was utilized. Temperature dependent parameter i.e., the cold filter plugging point (CFPP) was examined according to EN 116:2015 [31] standard. These necessary measurements were done with the ISL FPP 5Gs portable instrument. In this study, the surface tension was measured with the LAUDA TD-1C tensiometer in accordance with the requirements of ISO 304:1985 [32].

All measurements were repeated three times. The average value calculated for these repetitions was used to prepare necessary figures with empirical results of this research.

Engine research was carried out in the Faculty of Mechanical Engineering at the Kazimierz Pulaski University of Technology and Humanities in Radom. Figure 1 shows view of the engine test stand equipped with 3—cylinder, water—cooled and 4—stroke, naturally aspirated Perkins AD3.152 diesel 
engine. In this engine a fuel is injected directly into the main combustion chamber. Fundamental, technical details of the AD3.152 diesel engine are listed in Table 2.

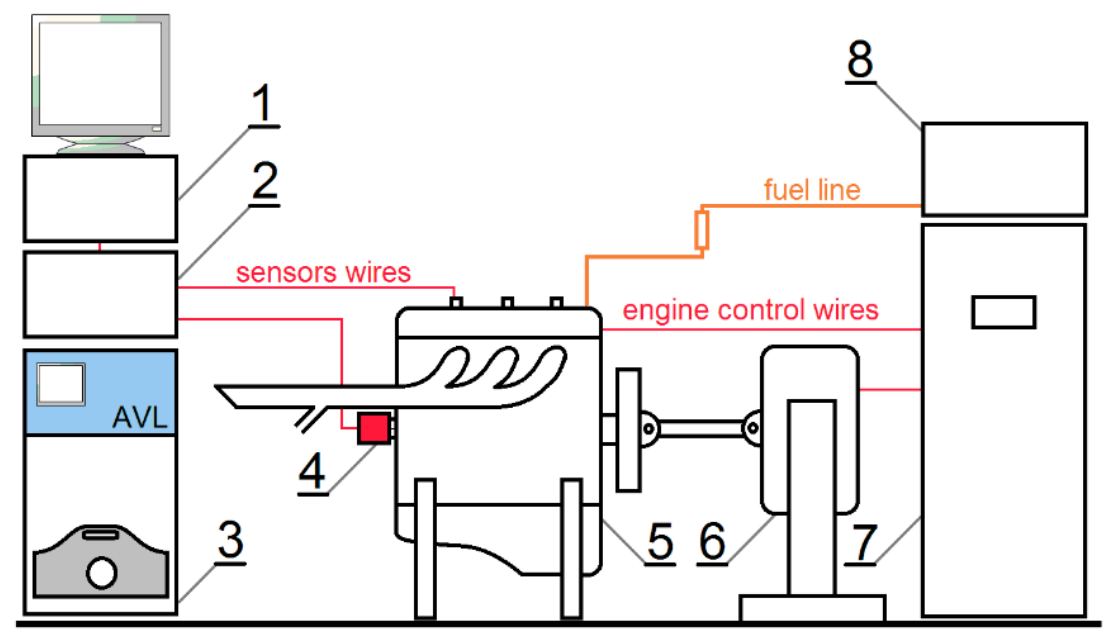

Figure 1. View of test stand equipped with the AD3.152 engine. 1-PC workstation equipped with KPCI 3110 measurement board; 2-sensors signals amplifier; 3-AVL 465 diGas analyzer; 4-crankshaft encoder; 5-AD3.152 engine; 6-dynamometer; 7—engine and dynamometer controller; 8—fuel tank.

Table 2. Technical specification of the AD3.152 diesel.

\begin{tabular}{lc}
\hline Parameter & Value \\
\hline Cylinder number & 3, in line \\
Engine capacity & $2502 \mathrm{~cm}^{3}$ \\
Compression value & 16.5 \\
Maximum power & $34.6 \mathrm{~kW}$ at $2150 \mathrm{rpm}$ \\
Maximum torque & $145-165 \mathrm{Nm}$ at $1200 \mathrm{rpm}$ \\
Crankshaft speed at idle run & $750 \mathrm{rpm}$ \\
Fuel injection system & Lucas-CAV type DPA \\
\hline
\end{tabular}

During research the engine was loaded by a hydraulic dynamometer. The in-cylinder pressure was measured by an AVL QC34D piezosensor with a sensitivity of $190 \mathrm{pC} / \mathrm{bar}$ and a measuring range of 0-25 MPa. The engine was also equipped with a CL80 needle lift sensor with a sensitivity of $0.5 \mathrm{~V} / \mathrm{mm}$ and a measuring range of $0-2 \mathrm{~mm}$. A needle lift sensor was made by polish company ZEPWN. Sensors' signals were sampled every 0.8 crank angle degree $\left({ }^{\circ} \mathrm{CA}\right)$. Research were carried out for nominal settings of tested engine in stationary conditions of work at 1000, 1200, 1400, 1600, 1800 and $2000 \mathrm{rpm}$ of the crankshaft under a load of $120 \mathrm{Nm}$. These measurement points are typical for the AD3.152 engine operated in middle and higher loads. In all such conditions 100 consecutive cycles of engine work were recorded and then processed to calculate the average value of each analyzed parameters. In this study the main analysis was focused on the fundamental combustion parameters i.e., the ignition delay (ID) and the engine overall efficiency (EOE). The ignition delay was determined as a ${ }^{\circ} \mathrm{CA}$ elapsed between the beginning of needle lift and the beginning of combustion process. The smoke opacity (SO) from tested engine was also measured with the AVL 465 diGAS analyzer with accuracy 1\%. In each measurement point the opacity was sampled at 15-s intervals and averaging 10 consecutive readings. The overall efficiency of the engine was calculated based on the fuel consumption measurement. In this study the amount of fuel combusted by the engine was measured volumetrically in three consecutive readings. The engine fuel supply and return pipes were connected with the cylindrical $500 \mathrm{~mL}$ dropping funnel with graduation marks. In each single test the time of $200 \mathrm{~mL}$ fuel consumption was 
measured and then the average value was calculated. Knowing the density and LHV of all tested fuels the engine overall efficiency (EOE) was calculated by the following equation:

$$
E O E=1 /(B S F C \cdot L H V)
$$

where:

BSFC-brake-specific fuel consumption;

LHV-lower heating value.

\section{Results and Discussion}

Physicochemical properties of all tested DEE/LO blends are listed in Table 3 and discussed below.

Table 3. Selected physicochemical properties of tested DEE/LO blends.

\begin{tabular}{lccc}
\hline Properties & LO10 & LO20 & LO30 \\
\hline Kinematic viscosity at $40{ }^{\circ} \mathrm{C}, \mathrm{mm}^{2} / \mathrm{s}$ & 11.793 & 7.392 & 4.457 \\
Density at $15{ }^{\circ} \mathrm{C}, \mathrm{g} / \mathrm{mL}$ & 0.9107 & 0.8943 & 0.876 \\
Lower heating value, $\mathrm{MJ} / \mathrm{kg}^{3}$ & 37.4 & 37 & 36.6 \\
Cold filter plugging point, ${ }^{\circ} \mathrm{C}$ & -8 & -16 & -24 \\
Surface tension, $\mathrm{mN} / \mathrm{m}$ & 29.9 & 27.1 & 23.6 \\
Flash point, ${ }^{\circ} \mathrm{C}$ & $<25$ & $<25$ & $<25$ \\
\hline
\end{tabular}

The resulting dependencies on the kinematic viscosity of DEE/LO fuel samples are shown in Figure 2. It should be noted that the following figures contain data of DEE/RO blend. These data were adopted from ref. [14].

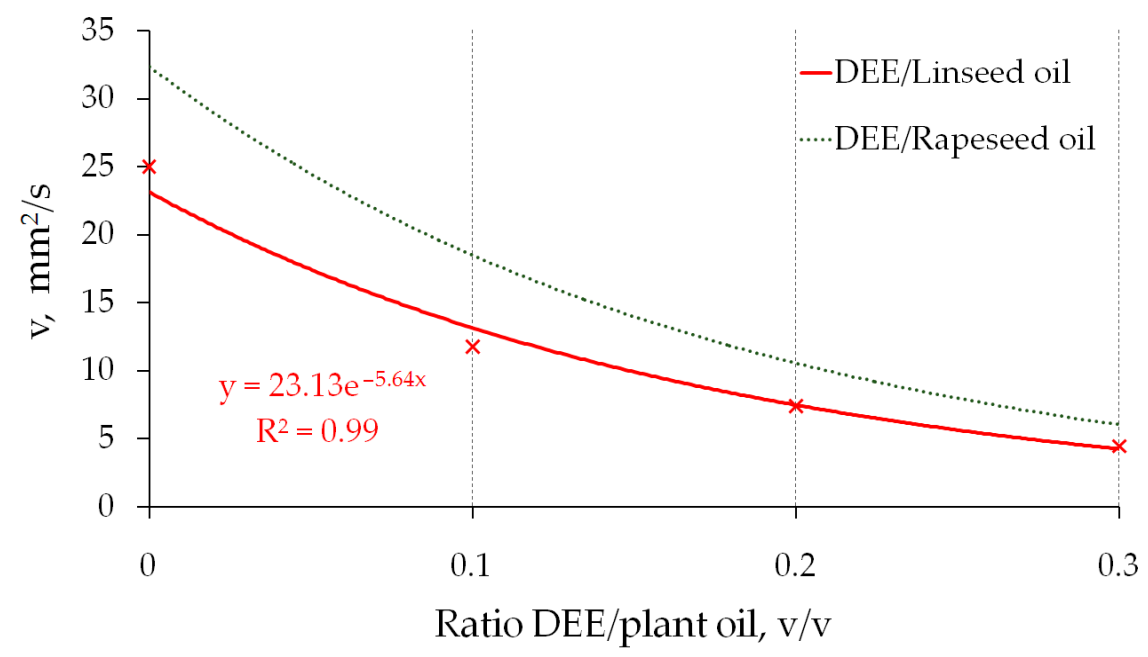

Figure 2. Kinematic viscosity (v) of DEE/LO and DEE/RO blend at $40^{\circ} \mathrm{C}$.

As mentioned before, the role of viscosity in the injection process seems to be the most important than any other parameter, therefore it must be set according to the values mentioned in standards: EN 590, ASTM D975 or EN 14214. Spray characteristics significantly can be improved with the use of blends compared to the neat linseed oil. Viscosity of $\mathrm{LO}$ as lower than for $\mathrm{RO}$ allowing it to reach more acceptable values for the diesel engine even with the small addition of DEE, until 30\%. For blends with DEE addition of $40 \%$ and more in volume variations in viscosity were not so realistic and were not influenced by oil type. This confirms the efficiency of blending compared to preheating and engine conversion for oil use. 
Modern automobiles must be operated in a wide range of ambient temperatures. Moreover, in modern diesel engines fuel was compressed even up to $200 \mathrm{MPa}$ or more and as a result it led to significant heating of diesel fuel. In addition, it should be noted that increasing of pressure increased activation energy and reduced the concentration of vacancies, therefore at high pressures the viscosity of liquids increased. Therefore, finding respecting between viscosity and temperature of diesel fuel is an important practical challenge to ensure efficient fuel injection.

Density, and also viscosity, is the temperature dependent parameter and there exists also the dependence between viscosity and density, which is mainly used in the oil industry. Like viscosity, density also has a great impact on the atomization process. Therefore, optimal values of those parameters must be reached for correct engine operation during all testing regimes.

Results shown in Figure 3 clearly indicate density dependence from DEE addition by a straight line with significant statistics outcomes in all cases with a confidence level of $95 \%$. It could be observed that oil type did not leave a serious impact on the density of all blends, therefore, LO can be used instead of $\mathrm{RO}$ to ensure optimal atomization process in diesel engine.

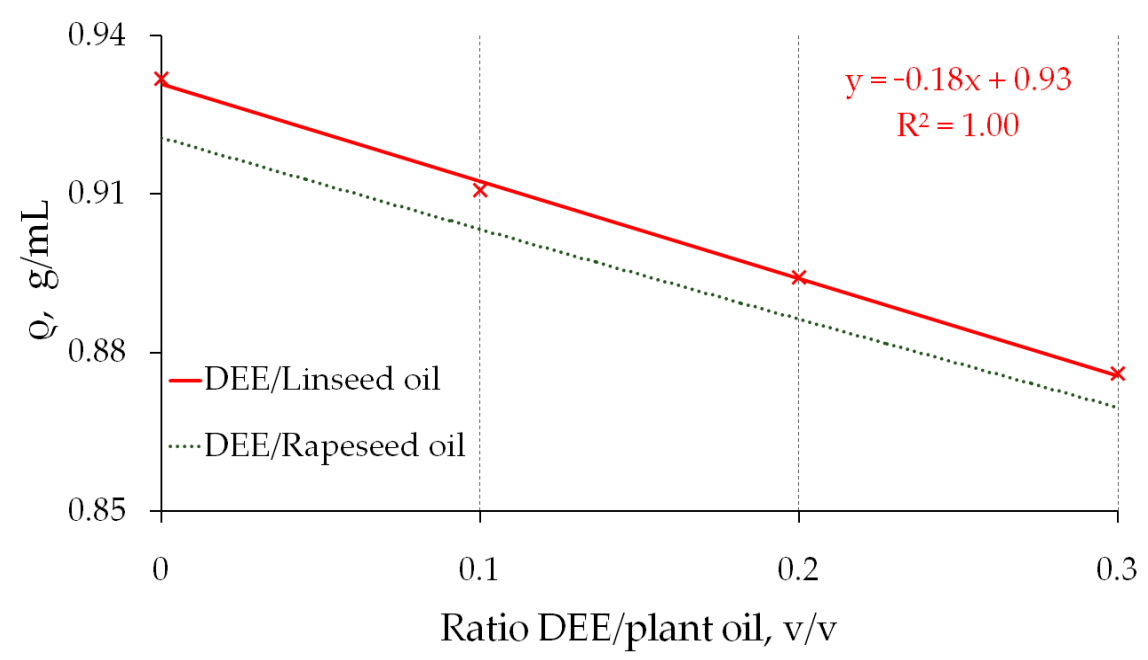

Figure 3. Density $(\rho)$ of DEE/LO and DEE/RO blend tested at $15^{\circ} \mathrm{C}$.

Another parameter, which could make the atomization process difficult is surface tension. Although European standards do not define values of surface tension not in the case of diesel fuel, neither to rapeseed oil, variation of this parameter leaves an important impact on the injection process. High values of surface tension and viscosity ensure worse fuel atomization in the form of larger diameter spray droplets.

It could be observed also in this research in the case of $\mathrm{RO}$, instead of $\mathrm{LO}$, which ensures significantly lower values of surface tension without blending (Figure 4). Like both previous parameters, also surface tension is temperature dependent, but it could be impacted also by pressure or even composition, like it is in the case of blends. In this research a linear decrease of surface tension based on DEE addition level to LO could be observed. 


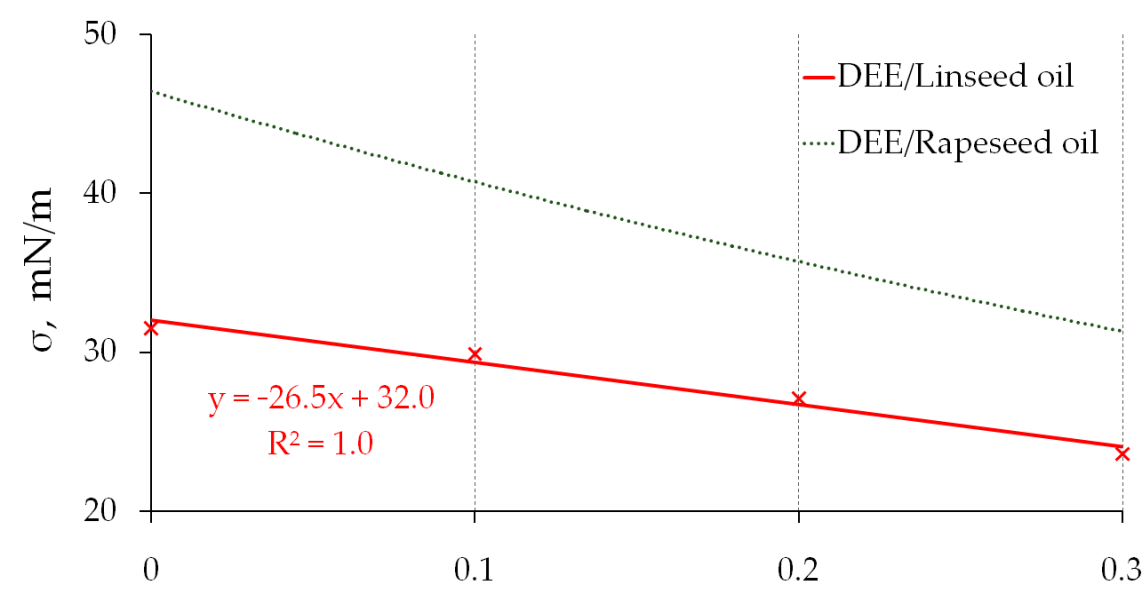

Ratio DEE/plant oil, v/v

Figure 4. Surface tension $(\sigma)$ of DEE/LO and DEE/RO blend.

CFPP was another parameter, which was analyzed in the case of LO and DEE blends. As it is one of the parameters, which is a direct indicator of engine low temperature operability additional attention has to be turned by engine operation in problematic climate conditions. As it is seen in Figure 5, LO indicates dependence from DEE by a straight line with tendency on reduction based on DEE addition. Even $10 \%$ addition to LO reduced CFPP to $-8{ }^{\circ} \mathrm{C}$, while RO could ensure such usage temperature only with $40 \%$ of DEE addition. Overall, addition of DEE improved low temperature properties for both oil types.

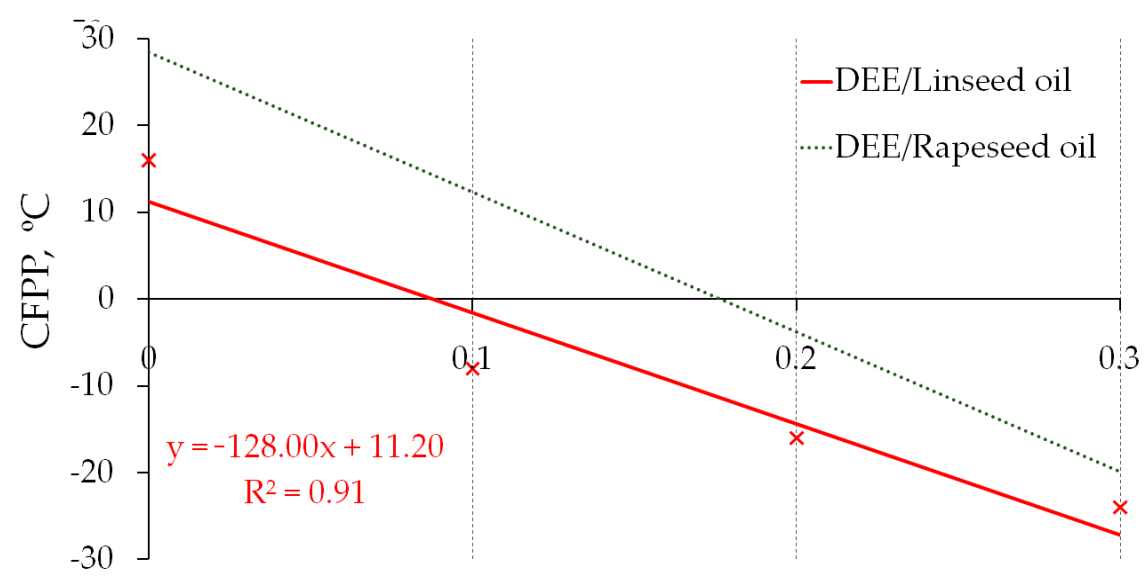

Ratio DEE/plant oil, v/v

Figure 5. CFPP $\left({ }^{\circ} \mathrm{C}\right)$ of DEE/LO and DEE/RO blend.

Results for LHV are presented in Figure 6. Here it is possible to observe the impact of the fuel composition on changes of LHV. Like all other vegetable oils, LO also reduced LHV compared with DF, but it also increased oxygen content by $10 \%$ while diesel almost did not have oxygen. Combination of LO with DEE allowed it to increase the total value of oxygen in the mixture resulting in a decrease of LHV proportionally of added DEE. The impact of DEE addition to RO on the variation of LHV had similar tendency like in the case of DEE/LO blends. The main difference is only a shift between values of LHV for LO and RO. 


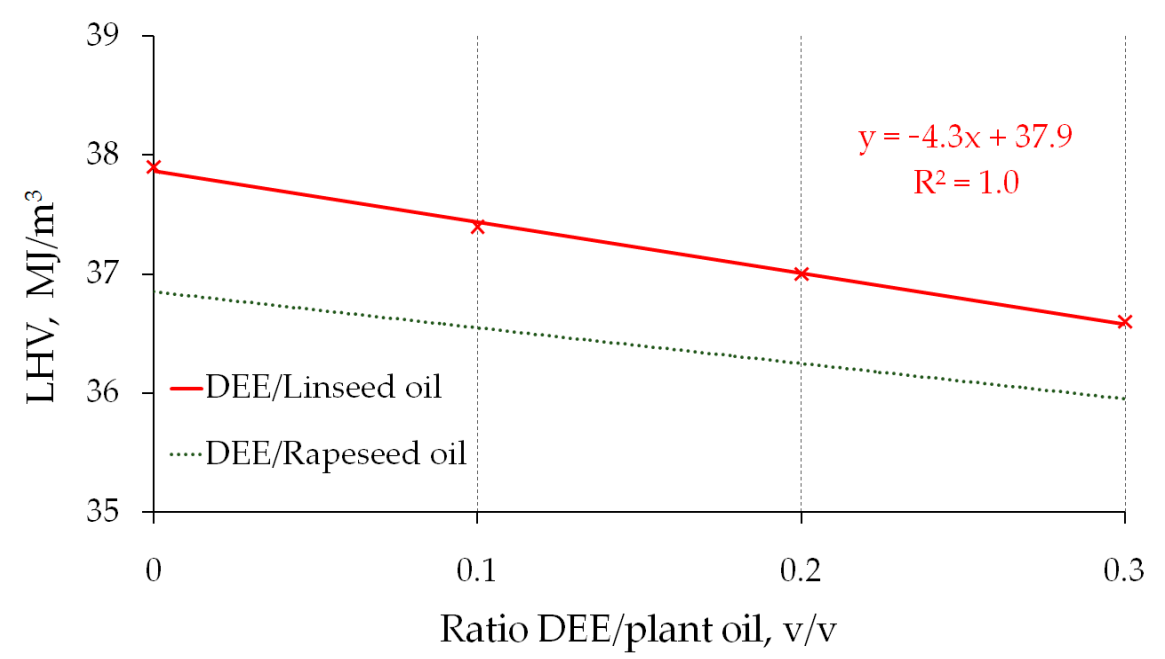

Figure 6. Lower heating value (LHV) of DEE/LO and DEE/RO blend.

In this work the selected parameters of combustion process were also investigated. In particular the in-cylinder pressure was recorded and processed to find out the beginning of combustion. Figure 7 presents the heat release rate (HRR) calculated for combustion of all tested fuels. In this case the beginning of combustion occurred earlier for DF than for LO.

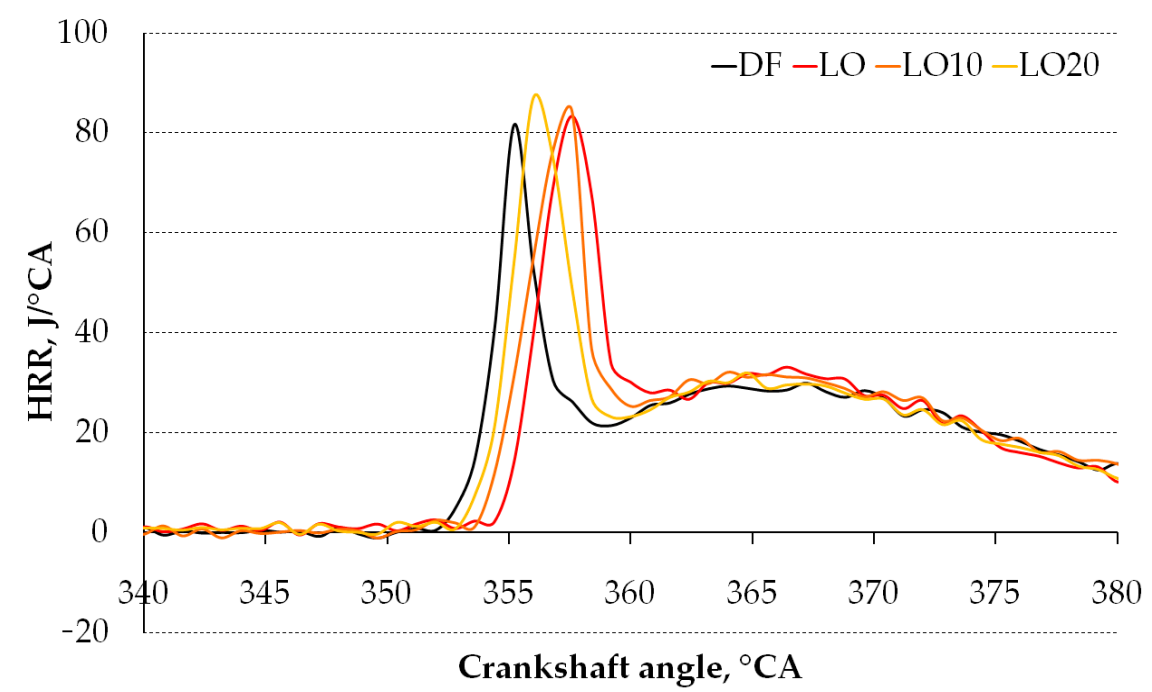

Figure 7. Heat release rate (HRR) for tested fuels in AD3.152 engine at $1200 \mathrm{rpm}$ and $120 \mathrm{Nm}$.

Taking into account the beginning of fuel injection the value of ignition delay (ID) was calculated. Research confirmed that ignition delay of LO was bigger $\left(0.8-2{ }^{\circ} \mathrm{CA}\right)$ than in case for DF, but it was observed directly at lower speeds, while in other conditions the gap slightly narrowed down (see Figure 8). As it was mentioned previously, there is the possibility to observe the impact of polyunsaturated fatty acids in $\mathrm{LO}$ allowing it to reach such a difference between $\mathrm{LO}$ and DF. Here it is seen an impact of physical delay influenced by fuel properties and composition [33]. Addition of DEE reduces the value of LO ignition delay together with viscosity resulting in a wider spray pattern. As it can be seen from Figure 8, ID of DF at larger engine speeds (2000 rpm) was similar to DEE/LO blends. Here it is possible to observe the impact of cylinder temperature and pressure on the chemical part of the delay period [33], which is more pronounced at higher speeds. 


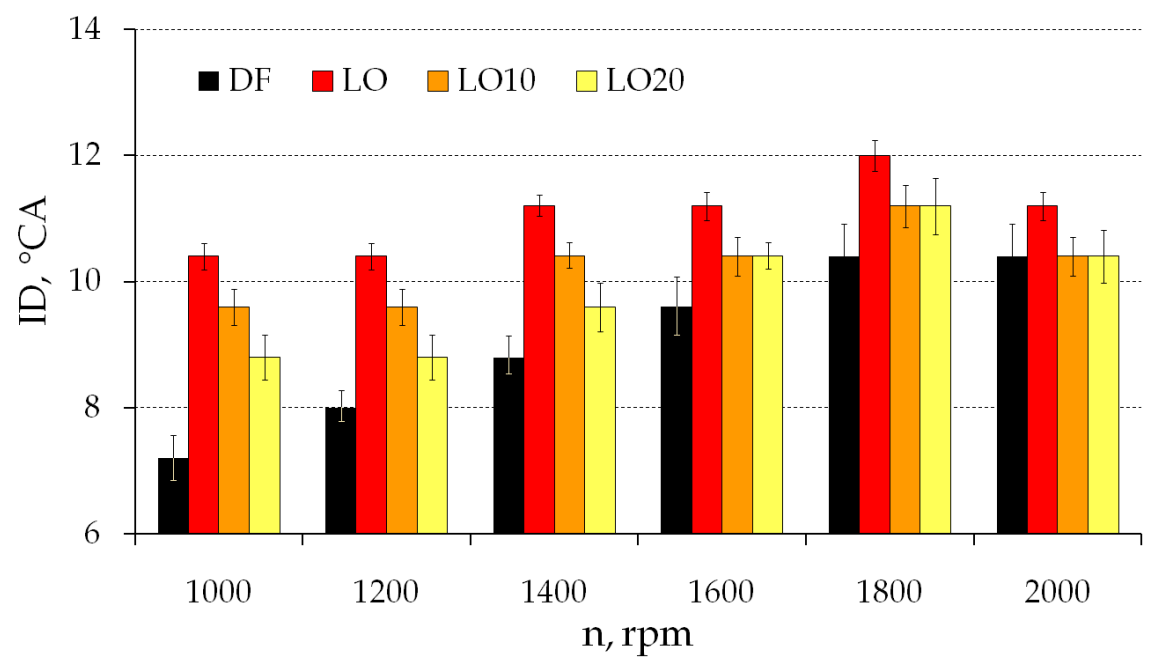

Figure 8. Variation of ignition delay (ID) for tested fuels in AD3.152 engine operated at $120 \mathrm{Nm}$.

The most fundamental and important engine parameter is its overall efficiency (OE). The value of this parameter was determined at all measurement conditions. Results suggest (Figure 9) that the engine overall efficiency powered with LO was slightly lower than for DF. It can be explained by weak combustion characteristics stimulated by higher viscosity and low volatility [34]. Moreover, the resistance of flow was adequately greater for more viscous fuel and for this reason it impacted on lowering of the engine overall efficiency. DEE, as the low viscosity component increased overall efficiency, especially according to high level blends like LO20. It can be also associated with lower self-ignition temperature and surface tension of DEE resulting in the complete combustion of tested blends.

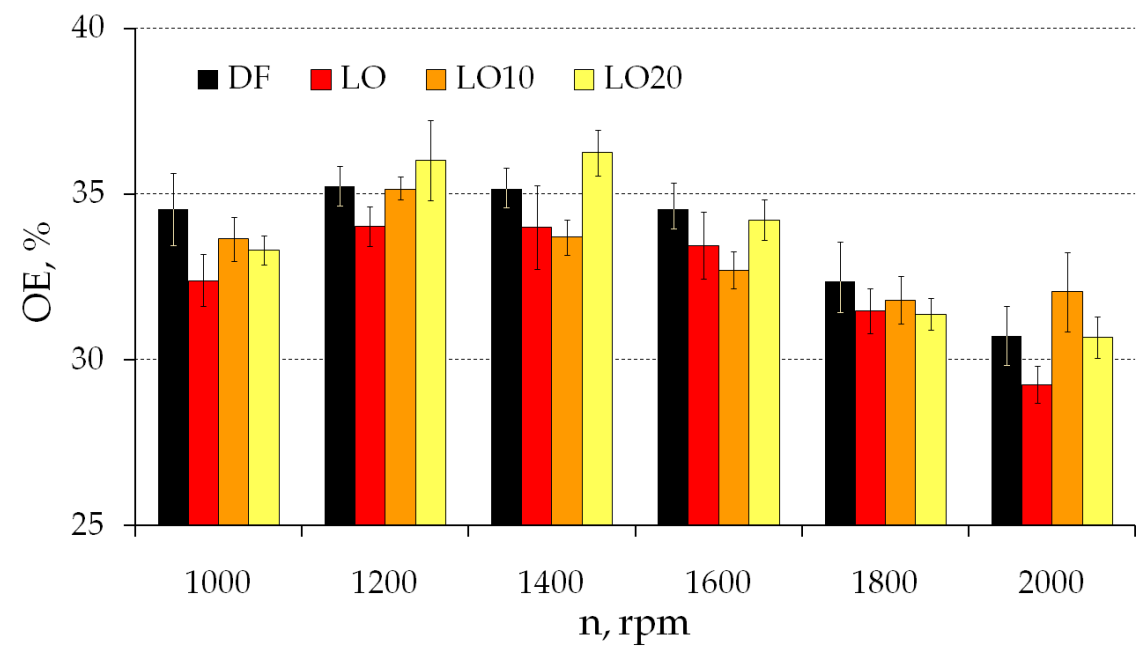

Figure 9. The overall efficiency (OE) calculated for the AD3.152 engine operated at $120 \mathrm{Nm}$.

Figure 9 seems to be inconsistent taking into account the results obtained at individual measurement points. Especially at the speed of $2000 \mathrm{rpm}$, the obtained changes in the efficiency of the engine work were not monotonic. At this measuring point, a mechanical rotational speed controller started to operate, which resulted in greater non-uniformity of fuel dosing, increasing the measurement uncertainty. The following Figure 10 was prepared for easier evaluation of the global impact of DEE added to LO on the efficiency of engine work. The figure shows the overall efficiency of the engine fuelled with specific fuel, calculated as the average of all measuring points. 


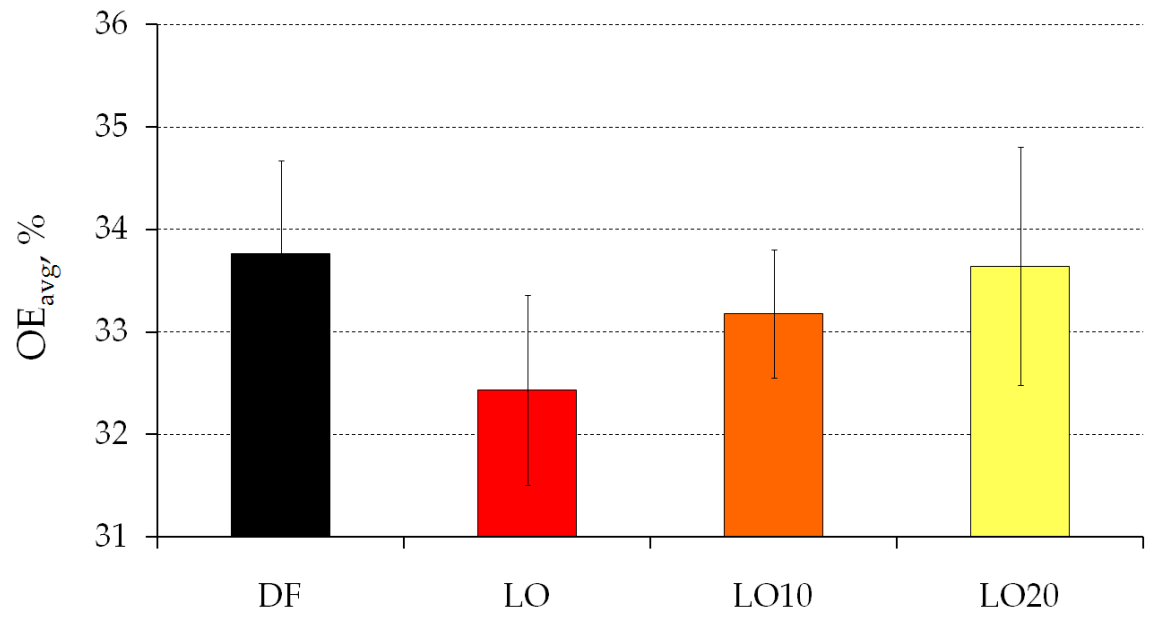

Figure 10. Average value of the overall efficiency $\left(\mathrm{OE}_{\mathrm{avg}}\right)$ calculated for the AD3.152 engine fuelled with tested fuels.

Figure 10 clearly indicates that combustion of DF in the tested engine occurs with the highest overall efficiency $33.8 \%$. In the case of LO this efficiency was reduced up to $32.4 \%$. Such results seem to be expected, as the test engine settings were adapted to the conventional fuel supply. Research on fuel blends has shown that the increasing addition of DEE to LO makes the physicochemical properties of such blends more and more similar to DF. For this reason also the overall efficiency of the engine increased with the addition of DEE to LO. The observed differences in this efficiency seemed to be comparable, but they are important in engine research.

Research did not confirm smoke reduction for LO (Figure 11), while it showed smoke reduction for blends with DEE due to its oxygen content. Usage of vegetable oils can lead to higher smoke opacity due to poor atomization and insufficient time for oxidation, but sometimes there could be observed also a reduction of smoke based on loads [35] and diffusion combustion intensity. Research confirmed that advance of injection timing, more pronounced for LO and LO10, results to oxidation of the soot particles due to a longer duration and higher temperatures during expansion stroke allowing one to conclude that an increase in ignition delay leads to poor combustion [36]. Besides that, combustion quality decreases also with unsaturation of LO [2]. DEE addition could resolve smoke opacity problem, at least at higher speeds.

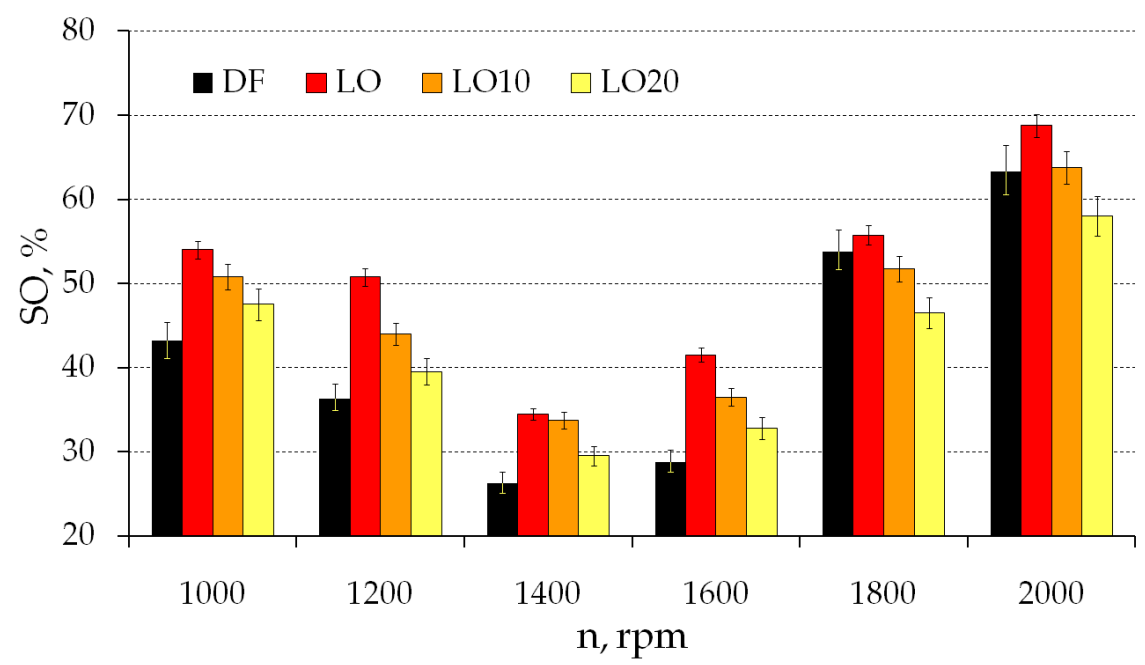

Figure 11. Variation of smoke opacity (SO) for the AD3.152 engine operated at $120 \mathrm{Nm}$. 
Overall, DEE left a better impact on smoke reduction than LO, where apart from the dominating factor, the molecular structure of DEE, also a positive impact of lower viscosity causing a better atomization could be observed.

\section{Conclusions}

Based on the literature review it can be stated that LO possess a wide range of properties, which could make it a considerable alternative to other vegetable oils. Results of this study showed that viscosity of LO was significantly lower in comparison with $\mathrm{RO}$ allowing it to reduce the amount of DEE added to plant oil. For example, LO containing 30\% DEE had the same viscosity as RO containing $40 \%$ of DEE. It should be pointed that both these mixtures allowed it to reach a viscosity value comparable to DF.

Research showed that DEE reduces the density of plant oils. However, values comparable to DF are possible only for mixtures containing more than $50 \%$ of DEE. Based on empirical data it was confirmed that the density of the DEE/LO blend is very well described by linear regression.

The linear relationship also describes well an impact of the DEE/LO ratio on the surface tension value. It was observed that DEE added to LO or RO reduces the surface tension of the blend. In the case of DEE/LO it should promote better atomization of the fuel injected into the combustion chamber. It is attributed to lower surface tension of DEE/LO blend compared with DEE/RO.

In the same time the addition of DEE to LO significantly reduced CFPP allowing one to use such blends in the winter season without the engine fuel preheating system. In this aspect the DEE/LO blends were more recommended compared with DEE/RO mixtures. CFPP of DEE/LO blends was also well described by a linear relationship.

Research has confirmed that the addition of DEE slightly reduces LHV of tested plant oils. It should be pointed that LHV of tested DEE/LO or DEE/RO blend is close to $36-38 \mathrm{MJ} / \mathrm{m}^{3}$, i.e., about $12 \%$ less compared with DF. For this reason the engine performance should be adequately reduced. It means that top power and torque of unmodified engine fuelled with alternative fuel blend will be lower compared with DF.

Based on the engine research, it was found that ignition delay of LO is significantly increased compared with DF. This was attributed to a considerably lower $\mathrm{CN}$ of plant oil. However, it was confirmed that DEE is an effective cetane improver and it allows one to reduce the ignition delay of LO. Simultaneously, smoke emission is also adequately reduced due the atomization quality of less viscous blend is better, and the consequence is lower smoke emission and slightly higher engine overall efficiency.

The results described in this paper encourage further research on DEE as an additive for diesel fuel and for renewable biodiesel. Our experiences showed that DEE is valuable for plant oils due to the physicochemical properties of these mixtures and are comparable with regular diesel fuel. However, additional tests on mixtures stability are necessary. Additionally, other tests focused on physicochemical properties mentioned in the EN 590 standard should be valuable. An impact of DEE in a blend with plant oils on emissions of harmful gas components from diesel engines should be continued taking into account constructions equipped with other injection systems. An impact of tested blends on the performances of diesel engines should be validated in other tests. Our experiences suggest that blends containing more than $20 \%$ DEE are not the best for engines operated in warm climate. DEE can form vapor lock affecting stability of the engine work.

Author Contributions: Conceptualization, K.G. and R.S.; methodology, R.L.; validation, K.G. and R.L.; formal analysis, R.L.; investigation, K.G. and R.S.; resources, R.S.; data curation, R.L.; writing-original draft preparation, R.S. and K.G.; writing-review and editing, K.G. and R.L.; visualization, K.G. and R.S.; supervision, K.G. and R.S.; project administration, K.G.; funding acquisition, R.L. All authors have read and agreed to the published version of the manuscript.

Funding: This research received no external funding.

Conflicts of Interest: The authors declare no conflict of interests. 


\section{Nomenclature}

$\begin{array}{ll}\text { ASTM } & \text { American Society for Testing and Materials } \\ \text { BSFC } & \text { Brake specific fuel consumption } \\ \text { CA } & \text { Crank angle } \\ \text { CFPP } & \text { Cold filter plugging point } \\ \text { CN } & \text { Cetane number } \\ \text { CO } & \text { Carbon monoxide } \\ \text { DEE } & \text { Diethyl ether } \\ \text { DF } & \text { Diesel fuel } \\ \text { EOE } & \text { Engine overall efficiency } \\ \text { HC } & \text { Hydrocarbons } \\ \text { HSDI } & \text { High-speed direct injection } \\ \text { ID } & \text { Ignition delay } \\ \text { LO } & \text { Linseed oil } \\ \text { LHV } & \text { Lower heating value } \\ \text { NOx } & \text { Nitrogen oxides } \\ \text { RO } & \text { Rapeseed oil } \\ \text { SO } & \text { Smoke opacity } \\ \mathrm{n} & \text { Crankshaft speed } \\ \rho & \text { Density } \\ v & \text { Kinematic viscosity } \\ \sigma & \text { Surface tension } \\ v / v & \text { Volumetric ratio } \\ & \end{array}$

\section{References}

1. Markiewicz, M.; Muslewski, L.; Pajak, M. Impact of biocomponent additive to diesel oil on values of selected functional parameters of transport means. Pol. J. Environ. Stud. 2020, 29, 3475-3483. [CrossRef]

2. Beg, R.; Rahman, M.; Bose, P.; Ghosh, B. Performance Studies on a Semi-Adiabatic Diesel Engine Using Vegetable Oil as Fuel; Sae Technology Paper Series; SAE International: Warrendale, PA, USA, 2002. [CrossRef]

3. Markov, V.A.; Kamaltdinov, V.G.; Savastenko, A.A. Petroleum diesel fuel and linseed oil mixtures as engine fuels. IOP Conf. Ser. J. Phys. Conf. Ser. 2017, 944, 1-8. [CrossRef]

4. Agarwal, D.; Kumar, L.; Agarwal, A.K. Performance evaluation of a vegetable oil fuelled compression ignition engine. Renew. Energy 2008, 33, 1147-1156. [CrossRef]

5. Kryshtopa, S.; Kryshtopa, L.; Melnyk, V.; Dolishnii, B.; Prunko, I.; Demianchuk, Y. Experimental research on diesel engine working on a mixture of diesel fuel and fusel oils. Transp. Probl. 2017, 12, 53-63. [CrossRef]

6. Chauhan, B.S.; Singh, R.K.; Cho, H.M.; Lim, H.C. Practice of diesel fuel blends using alternative fuels: A review. Renew. Sustain. Energy Rev. 2016, 59, 1358-1368. [CrossRef]

7. Rakopoulos, D.C. Combustion and emissions of cottonseed oil and its bio-diesel in blends with either n-butanol or diethyl ether in HSDI diesel engine. Fuel 2013, 105, 603-613. [CrossRef]

8. Krishna, R.; Banderwar, A.G.; Dongare, V.K. Experimental investigations of blending diethyl ether in karanja vegetable oil using a multi-cylinder diesel engine. Int. J. Res. Innov. Technol. 2014, 1, 70-73.

9. Geo, V.E.; Nagarajan, G.; Nagalingam, B. Studies on improving the performance of rubber seed oil fuel for diesel engine with DEE port injection. Fuel 2010, 89, 3559-3567. [CrossRef]

10. Delalibera, C.H.; Johann, A.L.; De Figueiredo, P.R.A.; De Toledo, A.; Weirich Neto, P.H.; Ralisch, R. Performance of diesel engine fuelled with four vegetable oils, preheated and at engine working temperature. Eng. Agríc. 2017, 37, 302-314. [CrossRef]

11. Krishnamoorthi, M.; Malayalamurthi, R. Availability analysis, performance, combustion and emission behaviour of bael oil-diesel-diethyl ether blends in a variable compression ratio diesel engine. Renew. Energy 2018, 119, 235-252. [CrossRef]

12. Ibrahim, A. Investigating the effect of using diethyl ether as a fuel additive on diesel engine performance and combustion. Appl. Therm. Eng. 2016, 107, 853-862. [CrossRef] 
13. Carvalho, M.; Torres, F.; Ferreira, V.; Silva, J.; Martins, J.; Torres, E. Effects of diethyl ether introduction in emissions and performance of a diesel engine fueled with biodiesel-ethanol blends. Energies 2020, $13,3787$. [CrossRef]

14. Górski, K.; Smigins, R. Selected physicochemical properties of diethyl ether/rapeseed oil blends and their impact on diesel engine smoke opacity. Energy Fuels 2018, 32, 1796-1803. [CrossRef]

15. Smigins, R.; Zakis, A. Impact of diethyl ether/rapeseed oil blends on performance and emissions of a light-duty diesel vehicle. Energies 2020, 13, 3788. [CrossRef]

16. Plank, M.; Wachtmeister, G.; Thuneke, K.; Remmele, E.; Emberger, P. Effect of fatty acid composition on ignition behavior of straight vegetable oils measured in a constant volume combustion chamber apparatus. Fuel 2017, 207, 293-301. [CrossRef]

17. Ghurri, A.; Kim, J.D.; Kim, H.G.; Jung, J.Y.; Song, K.K. The effect of injection pressure and fuel viscosity on the spray characteristics of biodiesel blends injected into an atmospheric chamber. J. Mech. Sci. Technol. 2012, 26, 2941-2947. [CrossRef]

18. Das, M.; Sarkar, M.; Datta, A.; Santra, A.K. Study on viscosity and surface tension properties of biodiesel-diesel blends and their effects on spray parameters for CI engines. Fuel 2018, 220, 769-779. [CrossRef]

19. Esteban, B.; Riba, J.G.; Baquero, G.; Puig, R.; Rius, A. Characterization of the surface tension of vegetable oils to be used as fuel in diesel engines. Fuel 2012, 102, 231-238. [CrossRef]

20. Hazar, H.; Aydin, H. Performance and emissions evaluation of a CI engine fuelled with preheated raw rapeseed oil (RRO) diesel blends. Appl. Energy 2010, 87, 786-790. [CrossRef]

21. Varde, K.S. Spray cone angle and its correlation in a high pressure fuel spray. Can. J. Chem. Eng. 1985, 63, 183-187. [CrossRef]

22. Shu, Q.; Wang, J.; Peng, B.; Wang, D.; Wang, G. Predicting the surface tension of biodiesel fuels by a mixture topological index method, at $313 \mathrm{~K}$. Fuel 2008, 87, 3586-3590. [CrossRef]

23. Knothe, G. Analyzing biodiesel: Standards and other methods. J. Am. Oil Chem. Soc. 2006, 83, 823-833. [CrossRef]

24. Park, J.Y.; Kim, D.K.; Lee, J.P.; Park, S.C.; Kim, Y.J.; Lee, J.S. Blending effects of biodiesels on oxidation stability and low temperature flow properties. Bioresour. Technol. 2008, 99, 1196-1203. [CrossRef] [PubMed]

25. Demirbas, A. Effects of moisture and hydrogen content on the heating value of fuels. Energy Sources 2007, 29, 649-655. [CrossRef]

26. Nettles-Anderson, S.L.; Olsen, D.B. Survey of Straight Vegetable Oil Composition Impact on Combustion Properties; Sae Technology Paper Series; SAE International: Warrendale, PA, USA, 2009. [CrossRef]

27. Venu, H.; Madhavan, V. Influence if diethyl ether (DEE) addition in ethanol-biodiesel-diesel (EBD) and methanol-biodiesel-diesel (MBD) blends in a diesel engine. Fuel 2016, 189, 377-390. [CrossRef]

28. European Standard EN 3838:2005. Crude Petroleum and Liquid or Solid Petroleum Products. Determination of Density or Relative Density-Capillary-Stoppered Pyknometer and Graduated Bicapillary Pyknometer Methods; European Committee for Standardization: Brussels, Belgium, 2005.

29. European Standard EN 3104:2000. Petroleum Products_Transparent and Opaque Liquids_Determination of Kinematic Viscosity and Calculation of Dynamic Viscosity; European Committee for Standardization: Brussels, Belgium, 2000.

30. ASTM Standard D240-02. Standard test method for heat of combustion of liquid hydrocarbon fuels by bomb calorimeter. In Annual Book of ASTM Standards; American Society for Testing of Materials: West Conshohocken, PA, USA, 2007.

31. European Standard EN 116:1997. Diesel and Domestic Heating Fuels. Determination of Cold Filter Plugging Point; European Committee for Standardization: Brussels, Belgium, 1997.

32. International Standard ISO 304:1985-Surface Active Agents—Determination of Surface Tension by Drawing up Liquid Films; ISO: Geneva, Switzerland, 1985.

33. Aldhaidhawi, M.; Chiriac, R.; Badescu, V. Ignition delay, combustion and emission characteristics of Diesel engine fueled with rapeseed biodiesel-A literature review. Renew. Sustain. Energy Rev. 2017, 73, 178-186. [CrossRef]

34. Sidibe, S.S.; Blin, J.; Vaitilingom, G.; Azoumah, Y. Use of crude filtered vegetable oil as a fuel in diesel engines state of the art: Literature review. Renew. Sustain. Energy Rev. 2010, 14, 2748-2759. [CrossRef]

35. Nandha, G.K.; Thundil, K.R. Effect of pongamia biodiesel on emission and combustion characteristics of DI compression ignition engine. Ain Shams Eng. J. 2015, 6, 297-305. [CrossRef] 
36. Narayana, R.J.; Ramesh, A. Parametric studies for improving the performance of a Jatropha oil-fuelled compression ignition engine. Renew. Energy 2006, 31, 1994-2016. [CrossRef]

Publisher's Note: MDPI stays neutral with regard to jurisdictional claims in published maps and institutional affiliations.

(C) 2020 by the authors. Licensee MDPI, Basel, Switzerland. This article is an open access article distributed under the terms and conditions of the Creative Commons Attribution (CC BY) license (http://creativecommons.org/licenses/by/4.0/). 